\title{
JUAN RAMÓN JIMÉNEZ 1900: HALLAZGO DEL ESLABÓN PERDIDO ENTRE LA SILVA MODERNISTA Y EL VERSO LIBRE HISPÁNICO.
}

\author{
Dolores Romero López de las Hazas* \\ Universidad de Salamanca
}

\begin{abstract}
A Isabel Paraíso del Leal
RESUMEN. Se ha afirmado reiteradamente que Juan Ramón Jiménez utiliza por primera vez el verso libre en Diario de un poeta recién casado en 1917. En este artículo se descubre que dicho metro fue utilizado ya en Ninfeas en 1900, donde hay poemas que no pueden ser considerados silvas por su irregularidad estrófica, variedad métrica y carencia de rima. El antecedente de dicho verso libre lo encontramos en En las orillas del Sar de Rosalia de Castro y en Castalia bárbara de Ricardo Jaime Freyre, libro que Rubén Dario prestó al poeta de Moguer.

ABSTRACT. The critics have repeatedly affirmed that Juan Ramón Jiménez uses free verse for the first time, in 1917, in Diario de un poeta recién casado. In this article, it is discovered that free verse was already used in Ninfeas, a book written by Juan Ramón Jiménez in 1900. There are poems that can not be considered as silvas because of their strophic irregularity, metrical variety, and lack of rhyme. The antecedent of this free verse is found in En las orillas del Sar by Rosalia de Castroand Castalia bárbara by Ricardo Jaime Freyre. The latter book, Rubén Dario lent to Juan Ramón Jiménez.
\end{abstract}

Se ha afirmado reiteradamente que Juan Ramón Jiménez utiliza por primera vez el verso libre en Diario de un poeta recién casado en $1917^{1}$, decisión importante para nuestra literatura pues supuso el éxito de la supresión de la rima, siempre más reacia a

\footnotetext{
"Becaria de Investigación "Formación de Profesorado Universitario" del Ministerio de Educación y Ciencia. C/ Cabeza de Vaca, $n^{\circ} 4,2^{\circ}$ A, 37004, SALAMANCA. Telf. (923) 230079.

1. Esta opinión la fomentan dos importantes críticos, por un lado Isabel PARAÍSO en su libro El verso libre hispánico, Gredos, Madrid, 1985, p. 200, y por otro Tomás NAVARRO TOMÁS en su excelente monografía Métrica española, Labor, Barcelona, 1983, p. 454.
} 
desaparecer del poema que otros parámetros rítmicos ${ }^{2}$. Tal afirmación viene corroborada por el propio Juan Ramón quien afirma que su verso libre "vino con el oleaje" $\mathrm{del}$ mar en su primer viaje trasatlántico. El poeta consideraba su Diario como su "mejor libro" y dice "me lo trajeron unidos al amor, el alta mar, el alto cielo, el verso libre, las Américas distintas y un largo recorrido anterior".

Isabel Paraíso ya se encargó de demostrar que tan anodina explicación no justificaba la presencia del verso libre en uno de los libros inéditos de 1911,Poemas impersonales. Incluso la asociación entre el ritmo del poema y el agua, como explicación del sentir poético intrínseco en el yo lírico, la había utilizado ya en 1903 en la crítica que dedica en El País al libro Soledades de su amigo Antonio Machado.

Es de todos conocido que el buen crítico y excelente poeta en que se convirtió Juan Ramón incurre, a veces, en contradicciones ${ }^{6}$. Indagando en el tema del verso libre hallamos estos dos textos:

1. "El verso libre de Unamuno es en gran parte orijen (sic) del mío y luego del de todos los que escribieron y escriben en verso libre en España y en Hispanoamérica. Y la reacción contra el modernismo vicioso formal, que la crítica suele regalarme a mí, viene principalmente de Unamuno"7.

2. "- El verso libre mío - observa - es muy diferente del de Unamuno que es bíblico; el de éste es unas veces versículo y otras tiene apoyatura en los agudos. El Cristo de Velázquez está escrito en verso blanco regular, y poemas como "Mi Salamanca", en verso sáfico"8.

Tales contradicciones despistan ineludiblemente a los críticos y convierten las afirmaciones de Juan Ramón en incognitas, a veces alejadas de lo que en la realidad ocurrió. La utilización del verso libre en la obra de Juan Ramón Jiménez aparece ya en 1900 , en tres poemas de Ninfeas. Si fuera verdad que el verso libre del Juan Ramón de

2. "En otros poetas hay verso libre como el del Diario, pero es que ha salido de alli. La mitad de la poesía moderna en España viene del Diario. Vea si no: León Felipe; Salinas y sus Presagios, publicado pormí en la Biblioteca deĺndice, en 1923; Moreno Villa y sus Evoluciones...", declaraciones realizadas por Juan Ramón a Ricardo GULLÓN y recopiladas por el crítico en Conversaciones con Juan Ramón Jiménez, Taurus, Madrid, 1958, p. 90.

3. GULLÓN, Ricardo: Ibidem, p. 84.

4. Citado por PARAÍSO DEL LEAL, Isabel: «El verso libre de Juan Ramón Jiménez en Dios deseado y deseante”, "Revista de Filología Española", LIV, pp. 253-268, cita de la p. 265. Nótese cómo Juan Ramón es consciente de que el verso libre que descubre en Diario es consecuencia de un proceso de madurez formal y espiritual. El sobrayado es mío.

5. Decía Juan Ramón: " $\mathrm{El}$ agua! Todas las rimas de jardín tienen gárgolas; el misterio del agua determina una verdadera obsesión en el alma de nuestro gran poeta, y esta música interminable y fresca es, a través de todo el libro, un poema sollozante con ritmo y gracia propios y con ensueño y queja y alma bañada de luz". Cita tomada de GULLÓN, Ricardo: Relaciones entre Antonio Machado y Juan Ramón Jiménez, Instituto di Letteratura Spagnola e Ispano-Americana, Università di Pisa, 1964, p. 73.

6. Léase el interesantísimo artículo de DEL RIO, Ángel: «Notas sobre crítica y poesia en Juan Ramón Jiménez: el modernismo", La Torre, año V, n. ${ }^{\circ} 19-20,1957$, pp. 27-47.

7. JIMÉNEZ, Juan Ramón: "El Modernismo. Cosmovisión. A mi modo de ver”, Aleria, edición con introducción y notas de Francisco Javier Blasco Pascual, Ediciones de la Universidad de Salamanca, Salamanca, 1983, p. 65.

8. GULLÓN, Ricardo: Conversaciones con Juan Ramón, ob. cit., p. 90. 
la segunda etapa proviene del utilizado por Unamuno, habría que buscar otro origen al verso libre que utiliza en Ninfeas, pues por aquel entonces los modernistas todavía no conocían nada de la producción poética del rector de Salamanca.

Juan Ramón Jiménez hizo su aparición en la vida bohemia modernista del Madrid finisecular invitado por Francisco Villaespesa y Rubén Darío quienes, tras leer en Vida Nueva algunas traducciones de Heine ${ }^{9}$ que había hecho el onubense y su poema "Las amantes del miserable"10, le enviaron una tarjeta postal en la que le llamaban "hermano" y le invitaba a ir a Madrid a luchar por el modernismo.

Juan Ramón había publicado algunos poemas en revistas de Sevilla, Huelva y Madrid y llevaba a la capital su libro Nubes para enseñarselo a los poetas que allí lo aguardaban. Nubes, libro que ya Juan Ramón había leído en Sevilla en la tertulia de Timoteo Orbe conocida con el nombre de "La Biblioteca"11, se componía "de una mitad de poesía anterior y otra modernista"12.

La primera mitad, Almas de violeta ${ }_{2}$ fue escrita desde sus 15 años y tenía influencia del romance de Heine - por ej. "Negras" - y de las estancias a lo Rosalía de Castro, Manuel Curros Enríquez o Jacinto Verdaguer - por ej. "El cementerio de los niños". Timoteo Orbe le aconseja: "No quite la parte primera - Almas de violeta -, Juanito, y mire bien la segunda - Ninfeas ${ }^{13}$-. Cuidado con esos "mercurialies" franceses ${ }^{14}$ y la joven América ${ }^{15 "}{ }^{16}$

Juan Ramón sabía que en su libro Nubes había dos secciones. Una de versos sencillos llenos de nostalgia y melancolía, con uso predominante del octosílabo inspirado en el romancero, Bécquer, Rosalía y Espronceda; otra sobrecargada de aparatosos decorados y de versos alejandrinos con influencia de Rubén Darío, de los latinoamericanos y del español Salvador Rueda.

Desde el punto de vista crítico es importante saber que la mayor parte de los poemas que integran Almas de violeta son anteriores en el tiempo a los de Ninfeas. El propio Ramos García, director de El Programa, en una semblanza que hace sobre el joven poeta, publicada el 3 de septiembre de 1899 , emite un juicio crítico sobre los poemas de autor de Platero y yo: "En sus primeras poesías notábase ese delicado romanticismo propio de la juventud, ora con lamentaciones de arrebato, parecidas a las de Lorbeiron (sic), ya dulces y melancólicas como las de Gustavo Bécquer, ya con tendencias, un

9. Los poemas de Heine a los que hace referencia son "E1 minero", "A mi amigo el orador revolucionario", "Pajarero y Pájaro" que fueron traducidos del alemán por Dionisio Pérez, el director de Vida Nueva, y que Juan Ramón versificaba a su antojo. Estos poemas fueron publicados en Vida Nueva en 1900.

10. Este dato es valiosísimo, como se verá más adelante.

11. "Fui a Sevilla invitado por el grupo de La Quincena y La Biblioteca, a leerles mi libre Nubes, que yo pensaba imprimir aquel año en Madrid. La Biblioteca estaba en un piso de la calle de Alabareda esquina a la de Tetuán encima de la dulcería de Buen Gusto". Dato tomado del libro de Juan Ramón JMÉNEZ: Mi Rubén Dario, Ediciones de la Fundación Juan Ramón Jiménez, Moguer, 1990, pp. 53-54.

12. JIMÉNEZ, Juan Ramón: "El modemismo poético en España y en Hispanoamérica", Alerta, ob. cit., p. 75.

13. Las dos acotaciones que hacen referencia a los libros son fruto de mi reflexión.

14. Sabemos que Juan Ramón leía asiduamente la revista Mercure de France.

15. La primera influencia que sufre Juan Ramón de Rubén Dario es a través de la Ilustración Española y Americana y de la revista catalana El Gato Negro.

16. JIMÉNEZ, Juan Ramón: "El modernismo poético en España y en Hispanoamérica", Alerta, ob. cit.p. 75. 
poquito amaneradas, a los escepticismos de Esproncesa, sin que se pudiera precisar marcada y definitiva tendencia"17. Sin duda, Juan Ramón Jiménez fue introduciendo, paulatinamente, en sus composiciones poéticas los nuevos ritmos de los que hablaba la crítica antimodernista ${ }^{18}$, pero sin olvidar su más inmediata tradición rítmica romántica como se puede ver tras el análisis métrico ${ }^{19}$ de Almas de violeta ${ }^{20}$ y de Ninfeas.

Si en el primer libro destaca, métricamente, lo tradicional sobre lo innovador, lo contrario ocurre en Ninfeas donde las innovaciones métricas son profusas y revolucionarias. Comienza el libro con un romance hexadecasílabo en el "Ofertorio". Dentro de los poemas estróficos hay que destacar la utilización de la sexta rima en su poema "Perfume", los cuartetos de trece sílabas en "Somnolenta" y serventesios dodecasílabos en "Tropical". Once poemas de un total de treinta y cinco son sonetos renovados tanto en la rima como en el metro. Utiliza sonetos de verso eneasílabo en "Mi ofrenda", el dodecasílabo en "Cementerio", el de trece sílabas en "Alma de la bruma", el alejandrino en cinco ocasiones ${ }^{21}$, y el octosílabo en "Marchita". Juan Ramón se aparta del metro tradicional influido por la nueva estética modernista siguiendo los pasos de Rueda y Rubén. Tanto en el primero como en el segundo se pueden encontrar precedentes en sus innovaciones métricas. Igualmente innovador es en aquellas composiciones en las que utiliza el pareado alejandrino que son dos, "El alma de la luna" y "Epigonal". Existen un total de trece composiciones que se pueden considerar dislintas variantes de silvas ${ }^{22}$ : la arromanzada en "Recuerdos", las libres o pares arromanzadas en otras siete composiciones $^{23}$, la silva par de versos sueltos ${ }^{24}$, la impar de versos sucltos en "Calma", la silva

17. PÉREZ DELGADO, Rafacl: “Primicias de Juan Ramón Jiméncz", Papeles de Son Armadans, XIX, 1974, p. 17.

18. Véase sobre este tema las siguientes referencias criticas: CELMA VALERO, M. ${ }^{\circ}$ Pilar: "El modemismo en la crítica coetánea" en La pluma ante el espejo, Universidad de Salamanca, Salamanca, 1989, pp. 21 -62; DELETTO Y PIÑUELA, José: “¿Qué es el modemismo y qué significa como escuela dentro del arte en general y de la literatura en particular?”, publicado en el libro de LITVAK, Lily: El modernismo, Taunus, Madrid, 1991, pp. 383-393; LITVAK, Lily: "La idea de decadencia en la critica antimodemista en España, (1888-1810), Hispanic Review, 45, 1977, pp. 397-412; MARTÍNEZCACHERO, José María: "Algunas referencias sobre antimodemismo español", Archivum, n. ${ }^{2}$ III, 1959, pp. 311-333; MARTÍNEZ CACHERO, José Maria: "Reacciones antimodemistas en la España fin de siglo", Actas del congreso internacional sobre el modernismo español e hispanoamericano, Diputación de Córdoba, Córdoba, 1985, pp. 125-143.

19. Hay muchos estudios que se dedican a desentrañar el ritmo de las formas métricas: QUILIS, Antonio: Métrica española, Ariel, Barcelona, 1985; TOMÁS NAVARRO, Tomás: Métrica española, Labor, Barcelona, 1983; LÓPEZ ESTRADA, Francisco: Métrica española del siglo XX, Gredos, Madrid, 1987; GILI GAYA: El ritmo en la poesía contemporánea, Universidad de Barcelona, Barcelona, 1956.

20. En Almas de violeta hay composiciones que reflejan el uso de una métrica tradicional como las cuartetas ("Azul"), las soleares ("Cantares"), y los romances. Ocho de los veinte poemas que hay en este libro son romances. Hay otro grupo de composiciones que fueron cultivadas por el modernismo: el serventesio ("Ofertorio"), la silva arromanzada, de tradición posromántica, ("i Silencio!" y "El Cementerio de los niños"), el soncto de endecasilabos con tercetos encadenados a través de pareados ("Nubes"), o el alejandrino ("Nochebuena") y el pareado, también alejandrino ("Almas de violeta"). Un tercer grupo, donde el poeta opta por ritmos más libres, estaria fomado por la silva par arromanzada en "Tristeza primaveral" y por la silva libre arromanzada del poema "Marina".

21. En "Ninfeas", "Mayas", "Alma de la nieve", "Siempreviva", "Cuadro".

22. Ricardo Gullón encontró, entre los papeles de Juan Guerrero, un poema de Antonio Machado titulado "Ninfeas" que según nota autógrafa, conservada en la Sala Zenobia-Juan Ramón de la Universidad de Puerto Rico, "ha seguido inédito hasta ahora". Este poema lo publicó Ricardo Gullón en 1962 y el joven amigo del onubense imita un tipo de silva libre consonante que aparece en algunos poemas de Ninfeas.

23. Son los siguientes poemas: "La canción de los besos", "Tarde gris", "Canción dela came", "El paisaje del corazón", "Otonal", "Melancólica", "Quimérica".

24. En "La cremación del sol" y "Sarcástica". 
libre con rima asonante de libre distribución en "Titánica", la silva libre con rima consonante variable que aparece en "Mis demonios" y tres composiciones en las que, sorprendentemente, aparece el verso libre ${ }^{25}$. En estas tres composiciones priman los versos pares, pero no se pueden considerar silvas pares de versos sueltos porque las estrofas son muy irregurales, y es esta irregularidad, añadida a las gran variedad métrica de sus versos, la que les diferencia de los anteriores ejemplos. El verso libre se caracterica por tener estrofas con un número desigual de versos, versos con un número desigual de sílabas que producen ritmos inarmónicos, aislamiento de la palabra, encabalgamiento y la novedad: no hay rima. Veamos los ejemplos:

1. "Tétrica" - analizo solamente las primeras paracstrofas:

$$
\begin{array}{lllllllllllllllllllll}
1 & 2 & 3 & 4 & 5 & 6 & 7 & 8 & 9 & 0 & 1 & 2 & 3 & 4 & 5 & 6 & 7 & 8 & 9 & 0 & \text { rima }
\end{array}
$$

1. - $-\mathrm{x}-$

2.- - - - x - / - - - - x

3. - $\mathrm{x}--1---\mathrm{x}-$

4. - - $-\mathrm{x}--1--\mathrm{x}_{-}-\mathrm{x}$

5. - - - - $\mathrm{x}-1-$

6. - - - - - $\mathrm{x}-$

7. - - - - $\mathrm{x}-$

8. - $\mathrm{x}--1--\mathrm{x}-$

9. - $\mathrm{x}--1--\mathrm{x}_{-}$

0. - $-\mathrm{x}---1--\mathrm{x}_{-}-$

1. - - - - $\mathrm{x}--1-$

2. $-\quad-\quad-\quad-x-$

3. $-\quad-x-$

4. $-\quad-x-$

5. - $-\mathrm{x}--1---\mathrm{x}-$

6. - - $\mathrm{x}--/-----$

7. - - $x--1-$

8. - - - - $\quad x-1-$

9. - $-\mathrm{x}-$

0. - - - - $\mathrm{x}-$ 
2. "Las amantes del miserable":

\section{$\begin{array}{lllllllllllllllllllll}1 & 2 & 3 & 4 & 5 & 6 & 7 & 8 & 9 & 0 & 1 & 2 & 3 & 4 & 5 & 6 & 7 & 8 & 9 & 0 & \text { rima }\end{array}$}

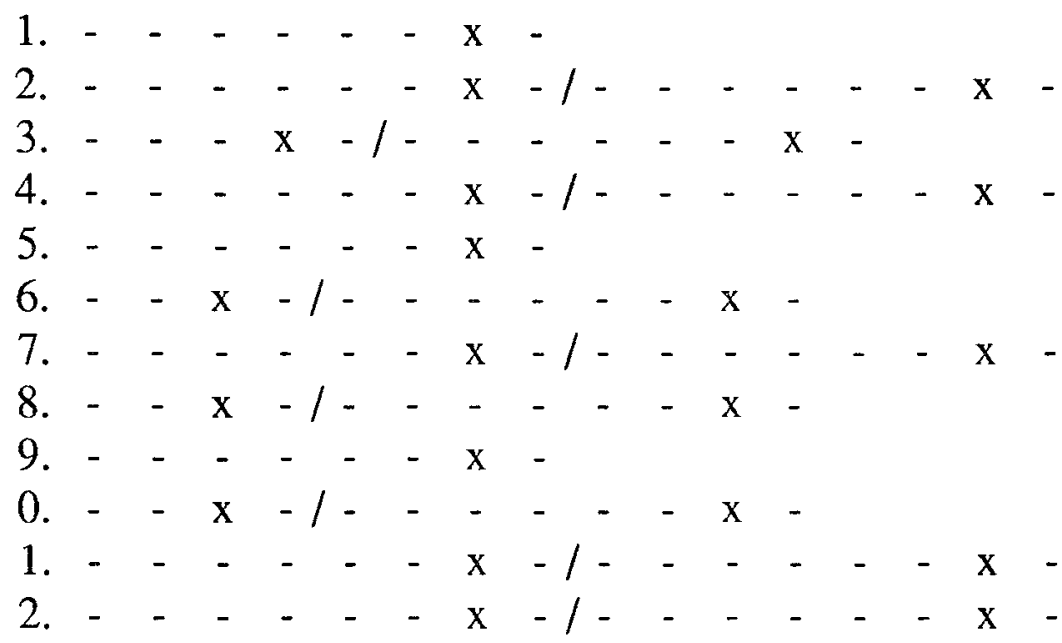

3. "Spoliarium"

$\begin{array}{lllllllllllllllllllll}1 & 2 & 3 & 4 & 5 & 6 & 7 & 8 & 9 & 0 & 1 & 2 & 3 & 4 & 5 & 6 & 7 & 8 & 9 & 0 & \text { rima }\end{array}$

1. $-\quad \mathrm{x}-\mathrm{x}-\mathrm{-}-\mathrm{-}-\mathrm{-}-\mathrm{x}-$

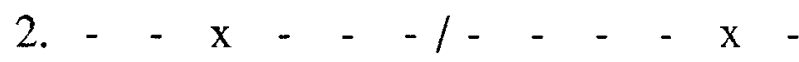

3. $-\quad-\quad-\quad-x$

4. $-\quad \mathrm{x}--\frac{1-}{-} \mathrm{x}-$

5.

6.

7. $-\mathrm{x}-\mathrm{x}-1--\mathrm{x}-$

8. - $-\mathrm{x}-$

9. - - - - - $-\mathrm{x}-/-\mathrm{x}_{-}-\mathrm{-}-\mathrm{x}-$

0. - $-\quad-\quad-\mathrm{x}-$

1. $-\quad-\quad-\quad \mathrm{x}-/$

La irregularidad métrica de la silva, como antecedente directo del verso libre, entronca ya desde finales del siglo XIX con el versolibrismo francés, iniciado en 1886 por Rimbaud, Kahn, Laforgue y Moréas. La distancia entre esta silva libre arromanzada y el verso libre es simplemente la rima y "sería Juan Ramón Jiménez el que quitaría la rima arromanzada a esta silva libre impar -a partir de Diario de un poeta recién casado, 1917 - inaugurando el tipo de silva libre más utilizado por la poseía del siglo $\mathrm{XX} " 26$.

26. PARAÍSO DEL LEAL, Isabel: “La silva y el modemismo”, El modernismo, Universidad de Valladolid, 1990, pp. 105-116, cit. p. 115. 
Cuando Rubén Darío y Villaespesa escriben al poeta de Moguer es porque han leído un poema suyo "Las amantes del miserable" que estaba compuesto en versos libres y del que Juan Ramón nos dice que era "más anárquico que ninguno"27. Este adjetivo, "anárquico", que Juan Ramón aplica a su poesía, es la mejor forma de definir este verso libre tan fuera de las normas métricas al uso y que, sin duda, fue una de las causas de las airadas críticas antimodernistas que sufrió el libro. En Godeón ${ }^{28}$ leemos: "se dedica a las lamentaciones y al ripio ${ }^{29}$ húmedo con la misma lacrimosidad que el fabricante de cognacs de Málaga, señor Jiménez... autor de Ninfeas, poesías tan abusivas como su título, al que le sobra la primera sílaba"30.

Lo que a principios de siglo se presentía como verso libre era mucho más simple que lo que ahora, pasado el surrealismo, consideramos como tal. En Mi Rubén Darío afirma Juan Ramón: “(...) Rubén Darío, de quien yo había leído antes (...) una composición en verso libre, "Friso" (...)"31. El poema "Friso" es un poema en endecasílabos que no tiene rima. ¿Era el verso libre para Juan Ramón un simple verso homosilábico y sin rima? No lo creo así, pero, en cualquier caso, frente a tal afirmación, es normal que considerase a los suyos versos "anárquicos".

Con estas conclusiones no se podrá seguir afirmando que Juan Ramón aprende el verso libre de Unamuno ${ }^{32}$, o incluso algunas otras erróneas consideraciones ${ }^{33}$ provocadas por el sentimiento adverso ${ }^{34}$ que Juan Ramón sintió hacia estas sus dos primeras obras y que ha contagiado a los críticos.

27. "El modemismo poético en España y en Hispanoamérica", Alerta, ob. cit. p. 75.

28. Revista especializada en criticas antimodemistas.

29. El subrayado es mio.

30. CAMOS, Jorge: “Cuando Juan Ramón empezaba. Crítica burlesca contra el modernismo", Ínsula, ns. 128-129, 1957 ,p. 9.

31. Ob. cit., p. 50.

32. Javier BLASCO PASCUAL, en la introducción al libro Alerta, p. 35, siguiendo las propias afirmaciones de Juan Ramón afirma que el verso libre de Diario de un poeta recién casado está netamente influido por el de Unamuno.

33. Quizá si se hubiera conocido antes la investigación que en este artículo se lleva a cabo, no habría habido afimaciones como la siguiente: 'El verso libre aparece, en efecto, en un libro inédito, Poemas impersonales, como evolución de la silva modernista. Es paralela esta aparición, pues, con su abandono del modernismo para entrar en otra etapa (...) Aunque sus primeras prosas daten ya de 1898, y siga escribiéndolas durante toda su vida, la evolución de su ideología poética viene marcada por el desarrollo ya visto: verso medido y rimado--verso libre- prosa. En los primeros libros la investigación formal consistió principalmente en la invención simbólica y en la creación de un universo poético". El texto no necesita glosa, la desatinada afirmación pertenece a Jorge URRUTIA en su artículo "Sobre la práctica prosística de Juan Ramón Jiménez y sobre el género de "Platero y yo", Cuadernos Hispanoamericanos, n. ${ }^{\circ}$ 376-378, octubre-diciembre, 1981. Para hacer honor a la verdad he de decir que precisamente fueron estas palabras las que me indujeron a realizar la presente investigación.

34. En 1907 en "Habla el poeta" Juan Ramón muestra su juicio sobre estas dos obras: "entre tanta frondosidad y tanta inexperiencia, lo mejor, lo más puro y lomás inefable de mi alma está, tal vez, en esos volúmenes", Renacimiento, VII, 1907, p. 422-426. Después, emitirá juicios adversos en contra de estos volúmenes a los que persiguió durante toda su vida para fundirlos con la inmaterialidad de las llamas. Léase el juicio sobre estos dos libros que aparece en su obra La corriente infinita, Aguilar, Madrid, 1961,pp. 134 y 232. Téngase presente la siguiente crítica: "Ya he dicho otras veces que Villaespesa dedicó todos los poemas que yo no habia dedicado en esos dos libros a escritores hispanoamericanos, y mandó las ediciones completas a América. Yo sólo recibí algunos ejemplares, y fue una pena, porque, si no, hubiese podido quemar luego aquellos libros impresos en morado y verde, como ahora otros de otros jóvenes, que estarán burlándose de mí por sus escondrijos", en "El modemismo poético en España y en Hispanoamérica", Alerta, ob. cit. p. 79. A pesar de esta reacción negativa hacia sus primeros libros, la crítica los ha seguido considerando como piezas importantes para el modemismo, como lo ponen de manifiesto los siguientes estudios: CERNUDA, Luis: Estudios sobre poesía española contemporánea, Colección Guadarrama de Crítica y Ensayo, 1957, Madrid, p. 124; GARCISOL, Ramón de: "Los primeros libros de poesía de Juan Ramón Jiménez", Cuadernos Hispanoamericanos, n. ${ }^{\circ} 135$, año 1961, pp. 382-397. 
Hoy en día, se tendría que hablar de dos tendencias en el verso libre juanramoniano. La primera proviene de las silvas de Rosalía de Castro en el libro En las orillas del Sar donde aparece la silva libre arromanzada, muy cercana ya al verso libre ${ }^{35}$; y de los latinoamericanos, y en concreto de Ricardo Jaime Freyre, quien en 1899 publica Castalia bárbara cuyas imágenes reproduce el poeta de Moguer en Ninfeas, llegando algunas de ellas a traspasar la frontera intimista desde la que se escribe Arias tristes.

En unas declaraciones afirma el "andaluz universal": "Antes de salir yo para Madrid ${ }^{36}$, Villaespesa me había mandado un montón de revistas hispanoamericanas. En ellas encontré, por vez primera, alguno de los nombres de aquellos poetas "distintos", que habían aparecido, como astros nuevos de diversa magnitud, por los países, fascinadores para mí desde niño, de la América española: Salvador Díaz Mirón, Julián del Casal, José Asunción Silva, Manuel Gutiérrez Nájera, Leopoldo Lugones, Guillermo Valencia, Manuel González Prada, Ricardo Jaime Freyre, Amado Nervo, José Juan Tablada, Leopoldo Díaz, ¿otros? y siempre Rubén Darío, Rubén Darío, Rubén Darío"37.

Más explícito es Juan Ramón cuando recuerda la admiración que tenían sus amigos de Madrid al genial Rubén Darío, y dice: "Villacspesa le servía de paje, y yo le reparaba un poco más de lado. Rubén Darío mismo nos iba dando los libros que recibía de sus amigos modernistas de América. A mí, por ejemplo, Castalia Bárbara de Jaime Freyres, cuadrado, cubierta rosa y oro" 38 .

Estas silvas y estos primeros versos libres serán olvidados tras su estancia en Francia en el Sanatorio Castel d'Andorte donde recupera a Bécquer y conoce profundamente a los simbolistas, más cercanos a su hipersensibilidad anímica. El poeta vuelve a recobrar la ilusión por la innovación métrica en 1911 en su libro Poemas impersonales, - pudiéndole haber influido el verso libre de Unamuno -, y tales innovaciones culminan en 1917 con el Diario. A la inversa de lo que pasó en su primera época ${ }^{39}$, Juan Ramón se sintió muy orgulloso de este verso libre, capaz de dar ágil forma a sus sentimientos. Si Juan Ramón rehusó seguir por la vía del modernismo colorista, por la que se encaminará su primer amigo, Villaespesa, fue por las durísimas críticas a que fueron sometidos sus dos primeros libros, sobre todo Ninfeas, más innovador.

Gran parte de la crítica, adversa al movimiento modernista, lo rechazó por la pose

35. "En conjunto, pues el poema "El alma"justifica los calificativos de Lugones: es "verdadera novedad" " "caso digno" - es ya, en nuestra opinión, versolibre, y no ya simple "silva modernista"; sin embargo la distancia que lo separa de las silvas arromanzadas pares y "de varias medidas" que enconträbamos en Rosalía no es excesiva, por lo que también podemos afirmar que esta variedad versolibrista, que en opinión de su creador, Jaime Freyre, habia surgido, en parte, "por imitación a los franceses, italianos y portugueses" y en parte "por intuición", resulta ser en realidad un paso adelante en evolución de la silva. De ahí que la denominemos silva libre". Este tex to está tomado de PARAISO DE LEAI., Isabel: "La silva y el modemismo", ob. cit., pp. 113-114.

36. El subrayado es mio.

37. "El modemismo poético en España y en Hispanoamérica", Alerta, ob. cit., pp. 75-76.

38. Ibidem, p. 78.

39. Considero que el verso libre de Ninfeas es más un alarde técnico, una forma de rebeldía, de despojar la poesía de las ataduras de la tradición retórica, que la búsqueda de un ritmo intimo que nace del propio artista como consecuencia de la armonía interior que brota de su alma, cfecto que consigue en el Diario. Por eso Rubén Darío y Unamuno son para el Juan Ramón de los años 30 dos formas de hacer modemismo: Dario encama el modemismo formal, mientras que Unamuno, discípulo de Bécquer, encarna el modernismo ideal. 
extravagante de sus poetas, otra se ensañó contra el "gongorino" lenguaje de sus "liliales" representantes y un tercer sector se sirve de su encarnizada pluma para arremeter contra las renovaciones métricas de estos jóvenes innovadores. Quiero traer aquí unos versos que aparecían en el Madrid Cómico el mismo año en que Juan Ramón publica sus dos primeras obras:

"¡Raro cantor de métrica larga, raro Rubén de ritmos exóticos! ¡Tanto rimar como todo nos carda, vamos a ser como tú unos despóticos! ¡Hay que ensanchar nuestro campo poético, hay que estirar a los versos de antes! ¡Hay que innovar! ¡Hay que hacer modernismo! ¿Hay que tirar la retórica ñoña! ${ }^{40}$

A ello contribuyó el poeta de Moguer en su poemario Ninfeas donde se encuentra el eslabón que une las distintas variedades de silva con el verso libre español. 
